\title{
Modelling the effect of temperature on crack onset strain of brittle coatings on polymer substrates
}

\author{
J.H. Waller, L. Lalande, Y. Leterrier *, J.-A.E. Månson \\ Laboratoire de Technologie des Composites et Polymères (LTC), Ecole Polytechnique Fédérale de Lausanne (EPFL), CH-1015 Lausanne, Switzerland
}

\section{A R T I C L E I N F O}

\section{Article history:}

Received 7 October 2010

Received in revised form 3 February 2011

Accepted 8 February 2011

Available online 24 February 2011

\section{Keywords:}

Failure

Coating

Polymer substrate

Elastic contrast

Internal strain

Temperature

\begin{abstract}
A B S T R A C T
The effect of temperature on the crack onset strain (COS) of brittle coatings on polymer substrates was investigated through a series of temperature-controlled tensile tests carried out in situ under an optical microscope. It was observed that the failure of such materials under tensile strain was strongly affected by temperature, but the exact behaviour was heavily dependent upon the type of material used. Below the glass transition temperature, $T_{g}$, of the polymer substrate, an increase in temperature led to a decrease in crack onset strain. Above the $T_{g}$, the substrate softening effects and corresponding shrinkage behaviour had a presiding role, leading to an increase in COS at elevated temperatures. The experimental COS data were modelled as a linear superposition of an intrinsic COS and the internal strain taking into consideration the respective influences of temperature dependent energy release rate for crack propagation and thermal expansion behaviour. Using adjustable values of the coefficient of thermal expansion and toughness of the coating, the model was found to accurately reproduce the change of COS with temperature of two different coatings on aromatic polyester substrates. The proposed approach enables, for any thin film composite with known material properties, the COS at any given temperature to be predicted.
\end{abstract}

(c) 2011 Elsevier B.V. All rights reserved.

\section{Introduction}

Brittle coatings such as inorganic gas-barrier layers, anti-corrosion layers and thin conductive coatings on flexible polymer substrates are finding ever increasing applications in diverse fields, from packaging and food applications [1] to optical components and flexible electronic and photovoltaic devices [2-4]. Mechanical integrity is an important consideration in the design, manufacture and operational life of such components. Often the processing of these composite films requires that the multilayer structures are subjected to thermo-mechanical loads, especially in the case of roll-to-roll processing. During such operations, there is a risk of damaging the brittle layers, thus reducing device performance.

The cracking behaviour of brittle films on various substrates at ambient temperatures has been well studied from both theoretical and experimental approaches. Theoretical descriptions are detailed in the comprehensive work of Hutchinson and Suo [5] with further developments to describe the failure of thin films on polymer substrates (e.g. [6]). Experimentally, a large volume of work has been carried out on the failure behaviour of coating layers of a wide range of properties on a variety of substrates, mainly metallic [7-9] and polymeric [10-16]. The failure of these coatings has been observed by optical microscopy, electron microscopy $[17,18]$ and

\footnotetext{
* Corresponding author.

E-mail address: yves.leterrier@epfl.ch (Y. Leterrier).
}

electrical resistance measurements [19-21], and the mechanics of crack initiation and propagation in a coating/substrate system are well understood $[5,22]$.

Interestingly, there have been few studies into the temperature dependence of the cracking process, yet temperatures well above $100{ }^{\circ} \mathrm{C}$ are often encountered, especially during processing. Yanaka et al. [13], conducted a series of experiments to explore the effect of temperature on the cracking of a $\mathrm{SiO}_{\mathrm{x}}$ coating on a polyethylene terephthalate (PET) substrate over a range from $26^{\circ} \mathrm{C}$ to $150{ }^{\circ} \mathrm{C}$. They observed that the number of tensile cracks at a given strain level decreased with increasing temperature, but noted that the strain at coating failure, also termed crack onset strain (COS), remained constant over the entire temperature range tested. This result is intriguing since tensile thermal stresses are expected to develop as the temperature is increased since the coefficient of thermal expansion (CTE) of the polymer substrate is usually higher than that of the inorganic coating, implying a decrease in the COS. In addition, softening of the polymer substrate upon heating is likely to change the energy release upon crack propagation, and hence the COS [5]. In the case of ultrathin coatings, with thickness in the sub-micron range, the analysis of the temperature influence on coating damage is, however, challenging. On the one hand the relevant material properties such as toughness and CTE are usually unknown. On the other hand the resolution of crack initiation and propagation under load requires in-situ methods, in which accurate thermal control is often difficult.

In the present work we looked at the effect of temperature on the cohesive failure of coatings on polymer substrates, with attention paid 
to the respective influence of temperature-dependent energy release effects and thermal stresses. The objective was to present a model to enable the COS to be predicted for any coating-layer system where the thermo-mechanical properties of the components are known.

\section{Theoretical influence of temperature on crack onset strain}

The linear superposition shown in Eq. (1) predicts that the COS of a coating is governed by the intrinsic crack onset strain $\left(\operatorname{COS}^{*}\right)$ and the internal strain $\left(\varepsilon_{\mathrm{i}}\right)$, both temperature dependent variables, each of which will be considered in the following sections.

$\cos (\mathrm{T})=\cos ^{*}(\mathrm{~T})-\varepsilon_{\mathrm{i}}(\mathrm{T})$

The negative sign in the equation is a convention: tensile strains are positive and result in a decrease of COS, and vice-versa for compressive strains.

\subsection{Calculation of the temperature-dependent intrinsic crack onset strain}

The tensile failure of coatings leads to the formation of cracks, and the energy release rate (ERR) during propagation of these cracks, $G_{s s}$, is related to the coating/substrate elastic contrast as expressed by the non-dimensional ERR $g(\alpha ; \beta)$, the integral of the crack opening displacement [23]:

$G_{s s}=\frac{1}{2} \frac{\sigma_{c}^{2} h_{c}}{\bar{E}_{c}} \pi g(\alpha ; \beta)$

where $\sigma_{c}$ is the coating stress, $h_{\mathrm{c}}$ and $\bar{E}_{c}=E_{c} /\left(1-\nu_{c}^{2}\right)$ are the thickness and plane strain modulus of the coating $\left(E_{\mathrm{c}}\right.$ and $\nu_{\mathrm{c}}$ are the Young's modulus and Poisson's ratio of the layer). The ERR, $g$, is a function of the Dundurs parameters $\alpha$ and $\beta$ which describe the elastic contrast between the substrate and the coating [24]. In the case of plane strain problems:

$\alpha=\frac{\bar{E}_{c}-\bar{E}_{s}}{\bar{E}_{c}+\bar{E}_{s}}$ and $\beta=\frac{\mu_{c}\left(1-2 v_{s}\right)-\mu_{s}\left(1-2 v_{c}\right)}{2 \mu_{c}\left(1-v_{s}\right)+2 \mu_{s}\left(1-v_{c}\right)}$

where $\bar{E}_{s}=E_{s} /\left(1-\nu_{s}^{2}\right)$ is the plane strain modulus of the substrate $\left(\mathrm{E}_{\mathrm{s}}\right.$ and $\nu_{\mathrm{s}}$ are the Young's modulus and Poisson's ratio of the substrate), and $\mu_{c}=E_{c} /\left(2+2 \nu_{c}\right)$ and $\mu_{s}=E_{s} /\left(2+2 \nu_{s}\right)$ are the shear moduli of the layer and substrate, respectively. For layers with same properties as their substrate, $\alpha=\beta=0$. A stiff layer on a soft substrate results in $\alpha \rightarrow 1$, whereas a soft layer on a stiff substrate results in $\alpha \rightarrow-1$. The function $g$ is primarily dependent on parameter $\alpha$, which is therefore more representative of layer/substrate elastic contrast than parameter $\beta$. For most layer/substrate combinations $0<\beta<\alpha / 4$ and in the present work we used $\beta=0$.

The intrinsic crack onset stress was obtained by equating $G_{s s}$ from Eq. (2) with the toughness of the coating $G_{c}$ [6]. The corresponding $\operatorname{COS}^{*}$ was thus expressed as:

$\cos ^{*}(\mathrm{~T})=\sqrt{\frac{2 G_{c}}{\bar{E}_{c} h_{c} \pi g(\alpha(\mathrm{T}) ; \beta(\mathrm{T}))}}$

This approach requires that coating flaws larger than a minimum length are present for the steady-state cracking conditions to apply. This will be checked in Section 4.4. The temperature dependence of the $\cos ^{*}$ arises from the temperature dependence of the elastic contrast function $\mathrm{g}$. An approximation of $\mathrm{g}$ was used (correlation coefficient $\mathrm{R}=0.9856$ ) by setting the fit parameter $\lambda=0$ and normalized crack length $\mathrm{a} / \mathrm{h}_{\mathrm{c}}=1$ ( $\mathrm{h}_{\mathrm{c}}$ is the coating thickness) as defined in [23]:

$g(\alpha ; \beta) \approx-2.5155\left[b^{2-2 s}\left(\frac{1}{2-2 s}-\frac{b}{3-2 s}\right)\right]_{b=1}^{b=0}=\frac{2.5155}{(2-2 s)(3-2 s)}(5)$

where $s$ is a stress singularity exponent function of $\alpha$ and $\beta$ [25]. The function $s$ is almost independent of $\beta$ for $\alpha>0.5$ and was approximated from the tabulated data in [23] (correlation coefficient $\mathrm{R}=0.99998$ ) as:

$s(\alpha) \approx 0.5+0.27548 \alpha^{1.2765}+0.18211 \alpha^{7.0168}$

Fig. 1 confirms the accuracy of Eqs. (5) and (6) to interpolate the numerical values of $g$ and $s$ tabulated in [23], respectively. It is evident that $g$ diverges as $\alpha$ approaches unity, i.e., as the substrate modulus becomes negligibly small compared to the coating modulus. This situation in fact corresponds to the case where the polymer substrate softens upon heating. The consequence is a reduction of $\operatorname{COS}^{*}$, which scales in inverse proportion with the square root of g (Eq. (4)). The knowledge of the temperature dependence of the elastic properties of the coating and of the substrate, and of the coating toughness enables the calculation of the $\operatorname{COS}^{*}$ using the above set of equations.

\subsection{Calculation of the temperature-dependent internal coating strain}

The internal strain of coatings on polymer substrates arises from a combination of effects [26]. Coating deposition strain (intrinsic strain) is temperature independent [27], but other contributions vary with temperature, these being: the strain resulting from the mismatch in thermal expansion coefficients of the coating and the substrate (thermal strain), shrinkage of the substrate due to molecular relaxation at temperatures above the glass transition (shrinkage strain) $[28,29]$ and the hygroscopic evolution with temperature (hygroscopic strain) [30,31].

In the present approach the temperature-dependent strains were grouped using an effective substrate CTE (i.e. the details of the expansion or contraction behaviour with increasing temperature which will be shown in the following were disregarded). The CTE of the coating layers was assumed to be independent of temperature over the investigated range. The coating internal strain at a temperature $\mathrm{T}$ was therefore expressed as:

$\varepsilon_{i}(T)=\int_{T_{0}}^{T}\left(\alpha_{s}(x)-\alpha_{c}\right) d x+\varepsilon_{\text {intrinsic }}$

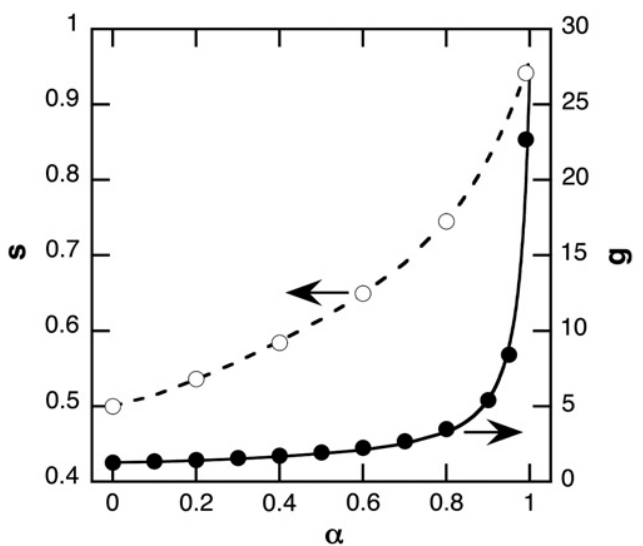

Fig. 1. Stress singularity exponent function s (open symbols: tabulated values in [23] dashed line: Eq. 6) and non-dimensional energy release rate $\mathrm{g}$ (closed symbols: tabulated values in [23]; solid line: Eq. 5). 
where $\alpha_{s}$ represents the effective, temperature dependent CTE of the substrate, $\alpha_{c}$ is the CTE of the coating and $\mathrm{T}_{0}$ is the coating deposition temperature. The knowledge of $\varepsilon_{\text {intrinsic }}$ and of these CTEs enables the calculation of $\varepsilon_{\mathrm{i}}(\mathrm{T})$ using Eq. (7).

\section{Materials and experimental methods}

\subsection{Materials}

Two types of coated polymer film were analysed. The first consisted of a coating of a $209 \mathrm{~nm}$ thick silicon oxide based layer (OXI) deposited at $25^{\circ} \mathrm{C}$ onto a substrate of $75 \mu \mathrm{m}$ thick polyethylene terephthalate (PET, Melinex 506, DuPont-Teijin Films). This sample was designated OXI/PET. The second sample type consisted of a trilayer coating, comprising a $0.8 \mu \mathrm{m}$ thick indium tin oxide (ITO) layer, a $0.23 \mu \mathrm{m}$ thick amorphous silicon (aSi:H) layer and a $0.1 \mu \mathrm{m}$ thick aluminium (Al) layer, on a $50 \mu \mathrm{m}$ thick polyethylene naphthalate substrate (PEN, TEONEX, DuPont-Teijin Films). The deposition temperature was close to $150{ }^{\circ} \mathrm{C}$ for the different layers. This sample type was developed for photovoltaic applications, and is designated $\mathrm{PV} / \mathrm{PEN}$. For each sample, the substrate was labelled with the machine direction, corresponding to the roll direction during manufacturing. The tests described in this work were systematically carried out along the machine direction. The multi-layers comprising the PV coating are considered as a single layer (PV) for the purpose of the work presented here, as fracture of one of the layers was considered as failure of the coating.

\subsection{Thermo-elastic properties}

The Young's modulus and effective CTE of the substrates were measured as a function of temperature using a dynamic mechanical analyser (DMA, TA instruments, Q800) in the tension film configuration. For both measurements, a rectangular sample was used, $5 \mathrm{~mm}$ wide, clamped at a length of $20 \mathrm{~mm}$. The heating rate was set at $5 \mathrm{~K} / \mathrm{min}$. A static force of $1 \mathrm{mN}$ was applied to the sample for the CTE measurement, the minimum applicable by the DMA, which was used as a dilatometer. The strain resulting from the application of this static force was below $510^{-6}$ and $210^{-5}$ for the PET and PEN, respectively, even at the highest considered temperatures, so that creep effects were negligible. For the modulus measurement, a strain rate of $0.001 \mathrm{~s}^{-1}$ and a low frequency of $1 \mathrm{~Hz}$ were used, which provided a first order approximation of the Young's modulus. The Poisson's ratio of the PET and PEN substrates was taken to be equal to 0.45 and 0.37 , respectively, from the manufacturer's data. Due to the coatings, in the case of both OXI and PV, being of an inorganic nature, their Young's modulus, Poisson's ratio and CTE were assumed to be independent of temperature over the range considered in this paper, and are summarized in Table 1. The Young's modulus of the OXI coating was obtained from nanoindentation, using a glass substrate. The Young's modulus of the Al, aSi:H and ITO layers which form the PV stack were calculated from the moduli of uncoated and coated PEN substrates, using tensile test measurements and the classical laminate theory. The other elastic data in Table 1 were taken from literature or assumed, and the corresponding elastic properties of the PV trilayer were calculated from the properties of each layer using the rule of

Table 1

Thermo-elastic data of inorganic coatings.

\begin{tabular}{lllll}
\hline Layer & $\begin{array}{l}\text { Thickness } \\
(\mathrm{nm})\end{array}$ & $\begin{array}{l}\text { Young's modulus } \\
(\mathrm{GPa})\end{array}$ & Poisson's ratio & $\begin{array}{l}\text { CTE } \\
\left(10^{-6} \mathrm{~K}^{-1}\right)\end{array}$ \\
\hline OXI & 209 & 128 & 0.235 & 15 \\
Al & 100 & 70 & 0.345 & 23.5 \\
aSi:H & 230 & 125 & 0.25 & 6 \\
ITO & 80 & 115 & 0.15 & 10 \\
PV & 410 & 110 & 0.25 & 12 \\
\hline
\end{tabular}

mixtures. The CTE data of the OXI and PV coatings were obtained from the modelling of the internal strain data as detailed later in the paper. The CTE values of the Al, aSi:H and ITO layers were taken from the literature. The calculation for the CTE of the PV stack from these three values using a laminate approach [32] would give a value of $1010^{-6} \mathrm{~K}^{-1}$, which is very close to the fitted CTE value.

\subsection{Determination of the coating internal strain}

Two alternative approaches were considered to obtain the internal strain of the coatings as a function of temperature, namely the analysis of the curvature of the coated substrates, and the application of Eq. (7) with the effective substrate CTE obtained by dilatometry.

In the curvature method, the internal strain was calculated from the radii of curvature of the films with and without the coating layers at selected temperatures, following the analysis of Röll [33]:

$\varepsilon_{i}=\frac{1-v_{c}}{E_{c}} \cdot \frac{-E_{s} h_{s}^{2}}{6\left(1-v_{s}\right) h_{c}}\left(1+\frac{h_{c}}{h_{c}}\left(4 \frac{E_{c}}{E_{s}}-1\right)\right) \cdot\left(\frac{1}{R_{2}}-\frac{1}{R_{1}}\right)$

where $h_{s}$ is the substrate thickness, $R_{1}$ is the radius of curvature of the uncoated substrate and $R_{2}$ is the radius of curvature of the coated substrate. The usual convention, where compressive stresses are negative was adopted. To obtain the radii of curvature at different temperatures, strips measuring $40 \mathrm{~mm}$ by $5 \mathrm{~mm}$ were cut from the sample foil, the longer dimension systematically in the machine direction. These strips were placed in a temperature controlled oven on a stand consisting of two polytetrafluoroethylene posts, $30 \mathrm{~mm}$ apart. The posts were shaped to minimise the contact area with the sample and thus reduce friction, allowing the sample to curve freely. A series of images were taken of the curved films over a range of temperatures up to $180^{\circ} \mathrm{C}$ and the displacement from the horizontal plane measured using digital image analysis. The displacements were measured in both a coating up and coating down configuration to negate gravity effects and were then used to calculate the radius of curvature of the film. The coating strain was thence calculated using Eq. (8) from the average of the calculated radii from four samples cut from the same foil to ensure accuracy.

In the dilatometry method, the internal strain was determined from the substrate CTE data using Eq. (7) with the CTE of the coatings reported in Table 1 and their intrinsic strain determined from the curvature method at their respective deposition temperature.

\subsection{Fragmentation test}

In the fragmentation test, the evolution of crack patterns in a brittle coating is monitored as a function of the uniaxial tensile load applied to the substrate [14]. Modelling of the experimental data gives access to the coating cohesive properties, which control cracking, and its adhesive properties, which control delamination. In the work presented here, the COS, defined as the strain at which the first cracks in the brittle coating start propagating, as a function of temperature was the focus. Rectangular samples, of gauge length $16 \mathrm{~mm}$ and width $5 \mathrm{~mm}$ were carefully cut from the foils along the machine direction using a razor blade. Tests were conducted in-situ under an optical microscope (Olympus BX60) using a miniature tensile testing apparatus (Linkam TSTE 350), equipped with a $200 \mathrm{~N}$ load cell. The nominal strain rate was $6.2 \times 10^{-5} \mathrm{~s}^{-1}$. Contactless video extensometry was used to overcome machine compliance effects with the accuracy of the measured strain greater than $10^{-3}$. Ink markers of dimension equal to approximately $100 \mu \mathrm{m}$ were drawn on the uncoated side of the polymer film and the change in the position of the centre of gravity of these markers allowed a precise measurement of the strain applied to the sample (see [20] for details). The apparatus had a sealed chamber testing environment, equipped with a heating element, allowing fragmentation tests to be carried out at a range of temperatures with 
accuracy better than $\pm 0.1^{\circ} \mathrm{C}$. An infra-red mirror was added to the original set-up, with the dual function of providing greater thermal stability inside the sample chamber, and protecting the objective lens of the microscope from excessive heat. OXI/PET samples were tested at $25^{\circ} \mathrm{C}, 50{ }^{\circ} \mathrm{C}, 80^{\circ} \mathrm{C}, 110^{\circ} \mathrm{C}, 140{ }^{\circ} \mathrm{C}$ and $170{ }^{\circ} \mathrm{C}$ and PV/PEN samples were tested at $25^{\circ} \mathrm{C}, 50{ }^{\circ} \mathrm{C}, 75^{\circ} \mathrm{C}, 95^{\circ} \mathrm{C}, 125^{\circ} \mathrm{C}$ and $150{ }^{\circ} \mathrm{C}$.

\section{Results and discussion}

\subsection{Influence of temperature on thermo-elastic properties}

The Young's modulus and effective CTE for each of the substrates were determined as a function of temperature, and are displayed in Figs. 2 and 3, respectively. The modulus of PEN was higher than that of PET over the whole range. As expected for such substrates, the modulus decreased with increasing temperature, exhibiting a large decrease around the glass transition of the polymer, equal to $80^{\circ} \mathrm{C}$ for PET, and $125^{\circ} \mathrm{C}$ for PEN.

The CTE of the two polyester substrates showed a positive, roughly linear increase with increasing temperature up to a point (around $100{ }^{\circ} \mathrm{C}$ for PET and $180^{\circ} \mathrm{C}$ for PEN) where it presented an inflection, and after which it became strongly negative. Above $100^{\circ} \mathrm{C}$, any water present in the polymer will strongly desorb from the sample, leading to a shrinkage of the substrate. Similarly, above the glass transition temperature, the molecules may relax their process-induced orientation state, and a shrinkage phenomenon results. These shrinkage effects were considered to be responsible for the change in CTE displayed for the substrates.

\subsection{Influence of temperature on crack onset strain}

The experimentally determined COS of OXI coatings on PET and PV coatings on PEN are shown as a function of temperature in Fig. 4. At ambient temperature, the PV coating displayed a COS equal to $1.16 \%$, a factor of two higher than the COS of the OXI coating equal to $0.53 \%$. As the temperature increased, the two coatings initially showed similar behaviour, i.e. the COS decreased. In both cases the measured COS at $150{ }^{\circ} \mathrm{C}$, was approximately half the value obtained at ambient temperature. The OXI/PET sample was tested to higher temperatures, and unexpectedly, at $170{ }^{\circ} \mathrm{C}$, the COS of the OXI coating showed an increase from the value measured at $140^{\circ} \mathrm{C}$. The large influence of temperature shown by both sample types reflected the build up of tensile thermal stresses resulting from the CTE mismatch between the constituents. It was also the consequence of the increasing elastic contrast with increasing temperature, as detailed in the following.

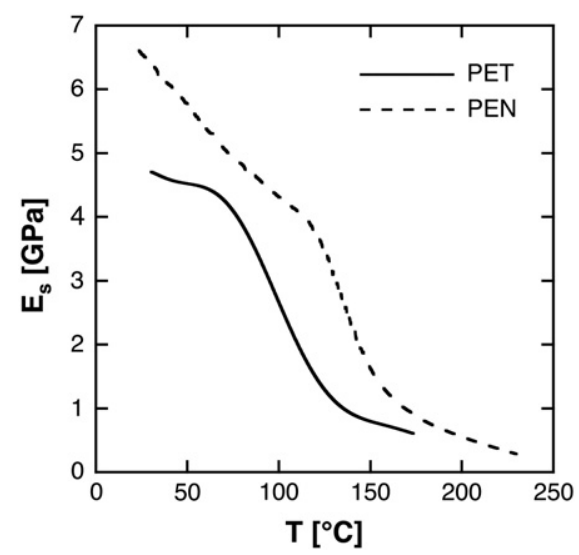

Fig. 2. Young's modulus vs. temperature for PET and PEN substrates.

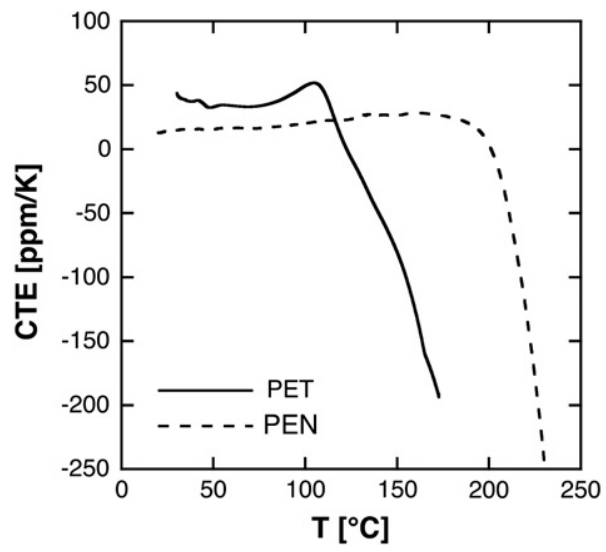

Fig. 3. CTE vs. temperature for PET and PEN substrates.

\subsection{Influence of temperature on coating internal strain}

Fig. 5 compares the values for the internal strain of the OXI and PV coatings obtained using the curvature and dilatometry methods. Considering first the OXI/PET samples, the coating internal strain was neutral at ambient temperature, which represented the intrinsic strain since deposition was carried out at this ambient temperature. As the temperature increased, up to approximately $100{ }^{\circ} \mathrm{C}$, an increasing internal strain to slightly more than $0.1 \%$ was observed. The CTE of the PET was positive over this range, and as such, the greater expansion of the substrate compared to the coating resulted in the coating experiencing a gradually increasing tensile strain. Above $100{ }^{\circ} \mathrm{C}$, the internal strain measurements showed a marked decrease, which manifested itself as a change in curvature direction upon heating an unconstrained film. Around $140{ }^{\circ} \mathrm{C}$, the shrinkage effects became dominant, and the coating layer changed from being under tension to a compressive state, which increased in magnitude with increasing temperature. The data obtained from the curvature measurements are compared with the prediction from the dilatometry measurements (Eq. (7)), using $\mathrm{T}_{0}=20^{\circ} \mathrm{C}$, an $\varepsilon_{\text {intrinsic }}=0$ and an adjustable $\alpha_{c}$ value found to be equal to $1510^{-6} \mathrm{~K}^{-1}$. The prediction was very good up to $100{ }^{\circ} \mathrm{C}$, and less accurate at higher temperatures but the overall trend was well reproduced. Clearly, the shrinkage of the PET substrate above $100{ }^{\circ} \mathrm{C}$ controlled the relaxation of the tensile strain and subsequent build up of a compressive strain in the OXI coating.

The internal strain measurements of PV coatings on PEN displayed a similar trend. The coating was under a $0.2 \%$ compressive strain at room temperature, which relaxed with increasing temperature over

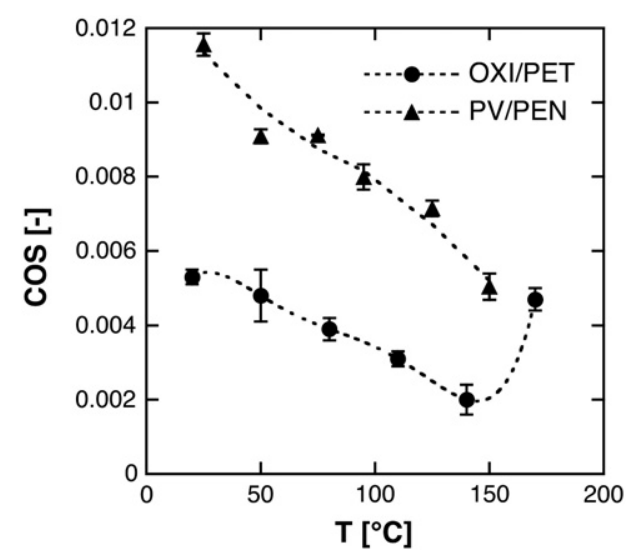

Fig. 4. Experimentally determined COS for OXI coatings on PET and PV coatings on PEN as a function of temperature. Dotted lines are provided as a guide for the eye. 


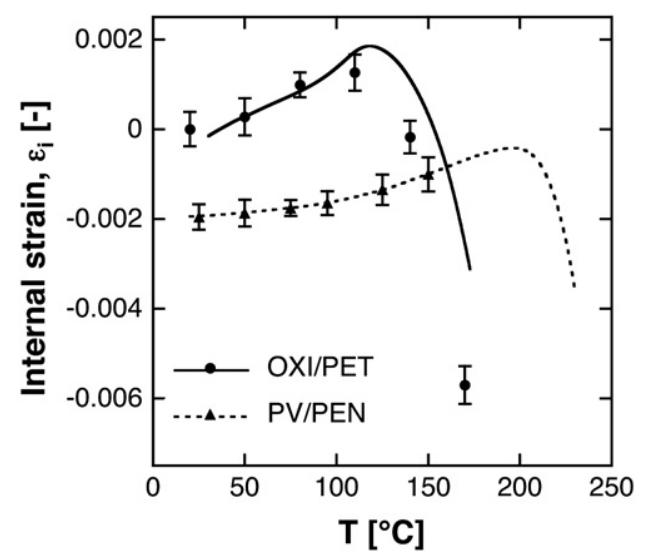

Fig. 5. Influence of temperature on internal strain of OXI coatings on PET (dots: values calculated using the curvature method; solid line: values calculated using the dilatometry analysis) and PV coatings on PEN (triangles: values calculated using the curvature method; dotted line: values calculated using the dilatometry analysis).

the range from ambient to $150{ }^{\circ} \mathrm{C}$, where it was approximately half the value as at $25^{\circ} \mathrm{C}$. This latter value of $-0.1 \%$ represents the intrinsic strain in the PV stack. The present behaviour had similar origins to the increase in strain for the OXI coatings on PET as described above. The build up of a tensile strain implies that the CTE of the PV stack was lower than that of the PEN substrate. The prediction from the dilatometry analysis (using $\mathrm{T}_{0}=150{ }^{\circ} \mathrm{C}, \varepsilon_{\text {intrinsic }}=-0.1 \%$ and adjustable $\alpha_{\mathrm{c}}=1210^{-6} \mathrm{~K}^{-1}$ ) shows a very good agreement, the difference being less than $210^{-5}$ over the investigated range. Interestingly, the dilatometry analysis predicted that the thermal stress increased up to $200{ }^{\circ} \mathrm{C}$ and then decreased due to the shrinkage of the substrate at high temperature to a compressive strain close to $0.4 \%$ at $230{ }^{\circ} \mathrm{C}$. We would also like to point out that the present approach enables the estimation of the CTE of such sub-micron coatings.

Fig. 6 compares the measured COS with calculated COS using Eqs. (1) and (7), assuming that the intrinsic $\operatorname{COS}^{*}$ was independent of temperature (i.e., disregarding the role of elastic contrast). This figure shows the influence of the temperature-dependent internal strain on the COS, for different values of COS*. It is evident that, for both types of films, no agreement could be achieved over the whole temperature range. The change of COS with temperature was thus not only

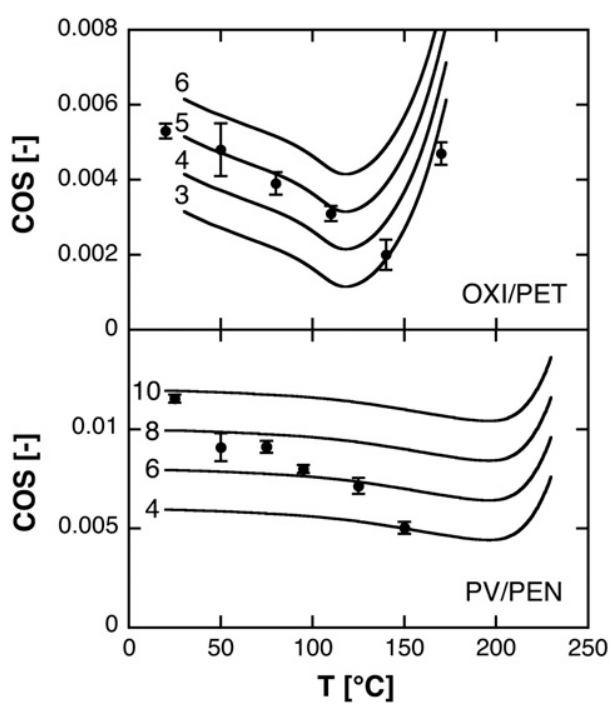

Fig. 6. Comparison between measured $\operatorname{COS}$ (dots) and calculated $\operatorname{COS}$ using Eqs. (1) and (7) (solid lines) assuming temperature independent $\operatorname{COS}^{*}$. Different $\operatorname{COS}^{*}$ values are tested, for the OXI/PET films ( $\operatorname{COS}^{*}$ in the range of 3 to $610^{-3}$ as indicated) and PV/PEN films ( $\operatorname{COS}^{*}$ in the range of 4 to $1010^{-3}$ as indicated).

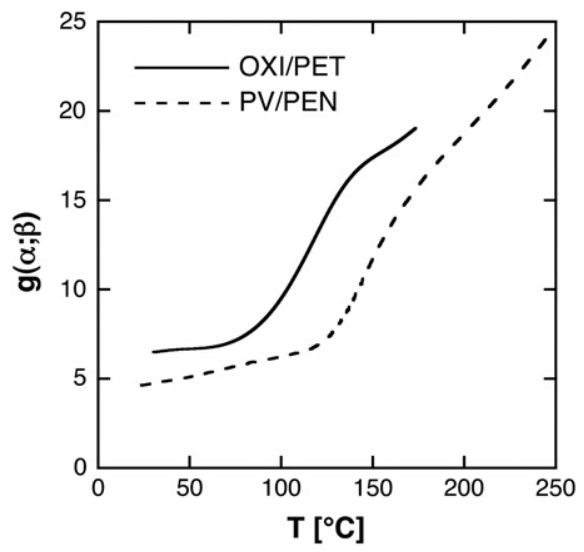

Fig. 7. Elastic contrast function $\mathrm{g}(\alpha ; \beta)$ vs. temperature for OXI coatings on PET and PV coatings on PEN.

dependent on the internal strain, but was also attributed to the elastic contrast and related energy release rate for cracking, which follows.

\subsection{Influence of temperature on intrinsic crack onset strain}

Fig. 7 shows the values of $g$ for both composite materials as a function of temperature. These data were calculated from the substrate modulus values shown in Fig. 2 and coating modulus data from Table 1, using Eqs. (3), (5) and (6). Quite clearly, the function $g$ mirrored the temperature dependence of the modulus. It was close to 5 for both polymers at room temperature, and increased threefold in the case of the OXI/PET film at $170{ }^{\circ} \mathrm{C}$, and fivefold in the case of the $\mathrm{PV} / \mathrm{PEN}$ film at $230^{\circ} \mathrm{C}$. The implication of this large increase of the ERR is that $\operatorname{COS}^{*}$, hence $\operatorname{COS}$, will decrease with increasing temperature due to the softening of the polymer substrates upon heating.

Eq. (4) was then used with these g values to calculate the temperature dependence of $\cos ^{*}$. The minimum flaw length required for the applicability of Eq. (4) was estimated as $2 \pi h_{c} g / 3$ [34]. It was found to be in the range from $6 \mu \mathrm{m}$ to $18 \mu \mathrm{m}$ for the OXI coating, and from 9 to $45 \mu \mathrm{m}$ for the PV coating, depending on temperature. These values are comparable with the sizes of micrometric defects present in the investigated coatings such as pin-holes and microcracks (approximately $1-10 \mu \mathrm{m}$ in the OXI coatings, and 5 to $50 \mu \mathrm{m}$ in the PV

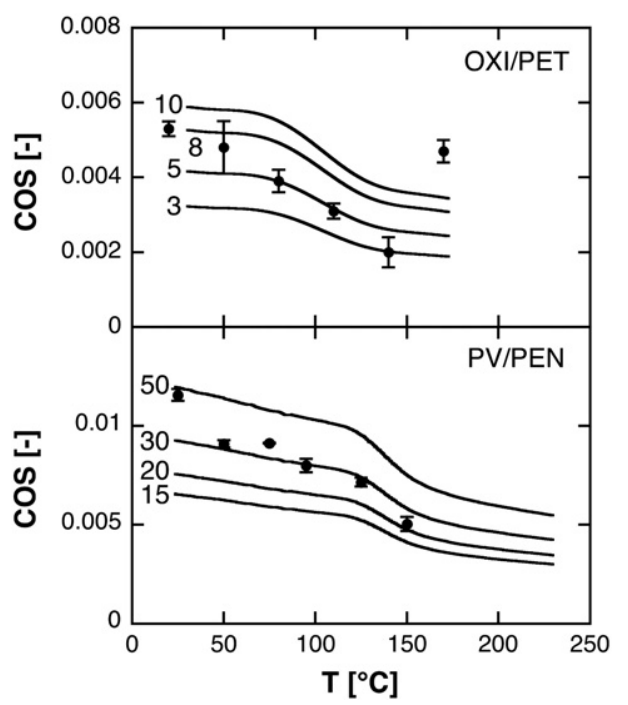

Fig. 8. Comparison between measured $\operatorname{COS}$ (dots) and calculated COS using Eqs. (1) and (4) (solid lines) assuming zero internal strain. Different coating toughness $G_{c}$ values are tested, for the OXI/PET films ( $G_{c}$ in the range of 3 to $10 \mathrm{~mJ} / \mathrm{m}^{2}$ as indicated) and PV/PEN films ( $G_{c}$ in the range of 15 to $50 \mathrm{~mJ} / \mathrm{m}^{2}$ as indicated). 


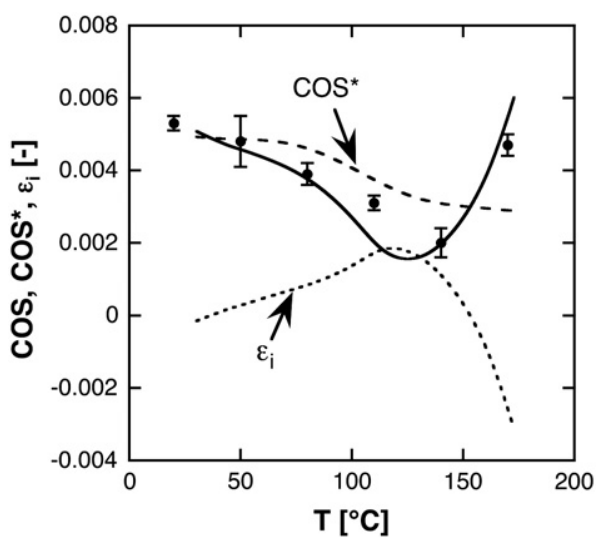

Fig. 9. Predicted COS (solid line) vs. measured COS (dots) for OXI/PET films as a function of temperature. Internal strain and $\operatorname{COS}^{*}$ predictions are also shown.

coatings). The calculated $\operatorname{COS}^{*}$ is shown in Fig. 8 for a range of coating toughness $G_{c}$ and compared with the measured COS values for the

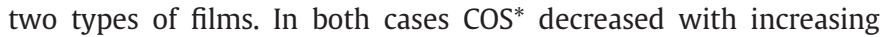
temperature. The influence of the glass transition is visible although not as strongly as for the modulus (Fig. 2) and g (Fig. 7) due to the square root scaling. Nonetheless, the influence of the increasing elastic contrast between the stiff coating and the increasingly softer substrate is considerable. However, no $G_{c}$ value provided a good fit to the data, especially for the OXI coatings. It is therefore clear that the

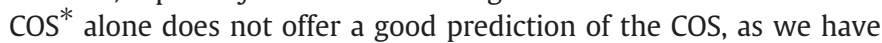
shown a marked change in the magnitude of the internal strain in the sample at elevated temperatures, which is not accounted for in the COS* calculation.

\subsection{Validation of the $\operatorname{COS}(T)$ model}

The validity of Eqs. (1), (4) and (7) to predict the COS of the OXI and PV coatings on the polymer substrates from the thermo-elastic properties of the constituents is tested in Figs. 9 and 10, respectively. Comparing the trend in internal strain to the measured COS, we see that the curves have an approximately mirror-image form. An increase in tensile internal strain was obviously linked to a corresponding decrease in the COS, and an increase in compressive strain had a corresponding increase in $\operatorname{COS}$. As for the $\mathrm{COS}^{*}$, the toughness values of the coatings were not available and were instead fitted to the experimental $\cos (\mathrm{T})$ data. For the OXI coating the best fit was obtained with a toughness $G_{c}=7 \mathrm{~J} / \mathrm{m}^{2}$, which is consistent with values reported for fused silica, in the $3-8 \mathrm{~J} / \mathrm{m}^{2}$ range [35]. For the PV/PEN samples, the value of $G_{c}$ was determined to be $20 \mathrm{~J} / \mathrm{m}^{2}$. This value is also consistent with the toughness of the aSi:H layer, the most brittle

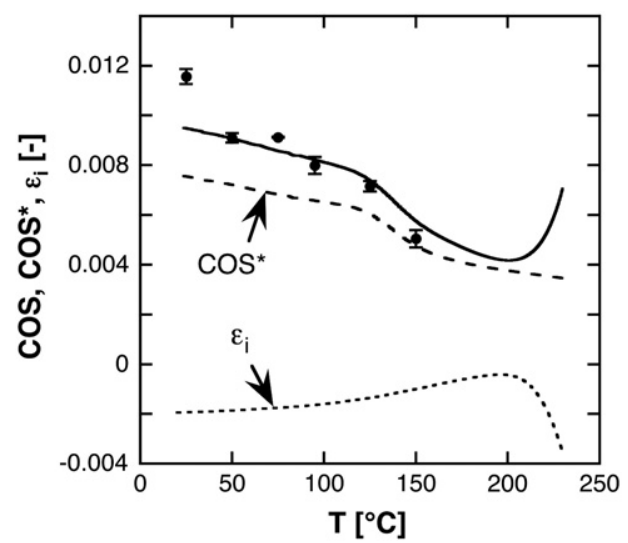

Fig. 10. Predicted COS (solid line) vs. measured COS (dots) for PV/PEN films as a function of temperature. Internal strain and $\operatorname{COS}^{*}$ predictions are also shown. layer in the stack, calculated to be equal to $16.0 \mathrm{~J} / \mathrm{m}^{2}$ from its COS and internal strain (obtained with a single layer aSi:H coating on the PEN substrate) using Eq. (4).

The predictive accuracy of the model is very high for the two types of coated films. The model correctly reproduced the observed increase of COS above $140^{\circ} \mathrm{C}$ for the OXI/PET samples, and predicted a similar behaviour at higher temperatures for PV/PEN samples. The approach, which combines $\mathrm{g}(\alpha ; \beta)$ and $\varepsilon_{\mathrm{i}}$ as a function of temperature therefore provides a robust tool to predict the influence of temperature on critical strain in brittle coatings on polymer substrates, and hence develop safe process windows for the deposition of such coatings and their conversion into final device applications.

\section{Conclusions}

The COS for brittle inorganic coatings on polymer substrates is strongly affected by the temperature, due to the combined action of substrate softening and expansion behaviour on heating. Below the $\mathrm{T}_{\mathrm{g}}$ of the polymer the COS decreases with increasing temperature whereas above the $T_{g}$ the opposite effect may occur. The factors controlling this effect were determined through analysis of the temperature dependence of the substrate modulus and related elastic contrast with the coating layer, and the temperature dependence of the coating internal strain. The effects of the residual strains in the coating as a function of temperature; a combination of intrinsic strains and thermal expansion, and the elastic contrast effects that arise between the brittle coating and the polymer substrate to determine the intrinsic crack onset strain were analysed. A model was developed to account for these assumed contributions to the COS, to enable for any thin film composite system with known material properties, the $\operatorname{COS}$ at any given temperature to be predicted. The approach was tested against two different types of thin inorganic coatings on polymer substrates. It was found to be accurate and correctly predict the complex temperature dependence of the COS of the investigated materials. It moreover enabled the estimation of the CTE and toughness of the sub-micron thick coatings.

\section{Acknowledgements}

The authors acknowledge the Swiss Commission for Technology and Innovation (CTI, project 9903.1 PFIW-IW) and the company VHF Technology SA for financial support and for the supply of samples.

\section{References}

[1] H. Chatham, Surf. Coat. Technol. 78 (1996) 1.

[2] L. Martinu, D. Poitras, J. Vac. Sci. Technol. A 18 (2000) 2619.

[3] G.P. Crawford (Ed.), Flexible Flat Panel Displays, John Wiley \& Sons, Chichester, England, 2005.

[4] M. Pagliaro, R. Ciriminna, G. Palmisano, ChemSusChem 1 (2008) 880.

[5] J. Hutchinson, Z. Suo, Adv. Appl. Mech. 29 (1992) 63.

[6] J. Andersons, J. Modniks, Y. Leterrier, G. Tornare, P. Dumont, J.-A.E. Månson, Theor. Appl. Fract. Mech. 49 (2008) 151.

[7] S. Ramaligan, Thin Solid Films 118 (1984) 335

[8] E. Harry, M. Ignat, A. Rouzaud, P. Juliet, Surf. Coat. Technol. 111 (1999) 177.

[9] J. Plojoux, Y. Leterrier, J.-A.E. Månson, F. Templier, Thin Solid Films 515 (2007) 6890.

[10] T.S. Chow, C.A. Liu, R.C. Penwell, J. Polym. Sci. 14 (1976) 1305.

[11] P.H. Wojciechowski, M.S. Mendolia, J. Vac. Sci. Technol. A 7 (1989) 1282.

[12] Y. Leterrier, J. Andersons, Y. Pitton, J.-A.E. Månson, J. Polym. Sci. B Polym. Phys. 35 (1997) 1463.

[13] M. Yanaka, Y. Tsukahara, N. Nakaso, N. Takeda, J. Mater. Sci. 33 (1998) 2111.

[14] Y. Leterrier, Prog. Mater. Sci. 48 (2003) 1.

[15] D.G. Howells, B.M. Henry, Y. Leterrier, J.-A.E. Månson, J. Madocks, H.E. Assender, Surf. Coat. Technol. 202 (2008) 3529.

[16] M.J. Cordill, A. Taylor, J. Schalko, G. Dehm, Metall. Mater. Trans. A 41A (2010) 870

[17] G. Rochat, Y. Leterrier, J.-A.E. Månson, P. Fayet, Thin Solid Films 437 (2003) 204.

[18] M.J. Cordill, JOM 62 (2010) 9.

[19] D.R. Cairns, R.P. Witte II, D.K. Sparacin, S.M. Sachsman, D.C. Paine, G.P. Crawford, R.R. Newton, Appl. Phys. Lett. 76 (2000) 1425.

[20] Y. Leterrier, L. Medico, F. Demarco, J.-A.E. Månson, U. Betz, M.F. Escola, M.K. Olsson, F. Atamny, Thin Solid Films 460 (2004) 156. 
[21] A. Pinyol, B. Meylan, D. Gilliéron, V. Mewani, Y. Leterrier, J.-A.E. Månson, Thin Solid Films 507 (2009) 2000.

[22] Z. Chen, B. Cotterell, W. Wang, Eng. Fract. Mech. 69 (2002) 597.

$23]$ J.L. Beuth, Int. J. Sol. Struct. 29 (1992) 1657

[24] J. Dundurs, J. Appl. Mech. 36 (1969) 650.

[25] A.R. Zak, M.L. Williams, J. Appl. Mech. 30 (1963) 142.

[26] P. Dumont, G. Tornare, Y. Leterrier, J.-A.E. Månson, Thin Solid Films 515 (2007) 7437.

[27] M. Ohring, The Material Science of Thin Films, Academic Press, London, 2002.
[28] B.F. Blumentritt, J. Appl. Polym. Sci. 23 (1979) 3205

[29] B. Haworth, Z. Dong, P. Davidson, Polym. Int. 32 (1993) 325.

[30] S.A. Jabarin, E.A. Lofgren, Polym. Eng. Sci. 26 (1986) 620.

[31] B.D. Harper, J.M. Rao, V.H. Kenner, C.H. Popelar, J. Electron. Mater. 26 (1997) 798.

[32] C.H. Hsueh, M.K. Ferber, Compos. A 33 (2002) 1115.

[33] K. Röll, J. Appl. Phys. 47 (1975) 3224.

[34] J. Andersons, P.H.M. Timmermans, J. Modniks, Int. J. Fract. 148 (2007) 233.

[35] S.W. Freiman, in: D.R. Uhlmann, N.J. Kreidl (Eds.), Glass science and technology, Elasticity and Strength of Glasses, vol 5, Academic Press, New York, 1980. 